\title{
RESENHA:
}

\section{Variações Santana: Um Percurso Admirável De Nietzsche À PsicANÁLISE}

Variações do ver: uma articulação entre Psicanálise e Nietzsche. SANTANA, Bruno W. Curitiba: CRV, 2019.

Pedro Brocco'

Johann Nikolaus Forkel, autor da primeira biografia sobre Bach, nos informa que um certo conde Hermann Karl von Keiserling, ex-embaixador russo na corte eleitoral da Saxônia, frequentemente passava por Leipzig e levava consigo o seu jovem e talentoso cravista, Johann Gottlieb Goldberg. O conde tinha frequentes problemas de saúde a passava noites sem dormir. Certa feita, von Keiserling comentou, na presença de Bach, que gostaria de ter algumas obras para Goldberg executar e que deveriam ter caráter ao mesmo tempo suave e vigoroso, para que ele pudesse ser consolado em suas noites sem dormir. Bach então imaginou que a melhor maneira de atender ao desejo do conde seria por meio de variações, cuja composição era considerava por ele, até aquele momento, uma tarefa enfadonha, devido ao fundamento harmônico repetido e semelhante que uma peça de variações comportava. No entanto, As Variações Goldberg que, embora tenham sido compostas por Bach, passaram à posteridade marcadas pelo significante de seu talentoso executor, se tornaram uma das composições favoritas de muitos ouvintes e apreciadores de música erudita.

Neste breve espaço de resenha, meu objetivo é apresentar ao leitor outra composição por meio variações: trata-se da obra Variações do ver: uma articulação entre Psicanálise e Nietzsche, escrita e executada com mestria por Bruno Wagner Santana.

\footnotetext{
${ }^{1}$ Membro associado do Corpo Freudiano Escola de Psicanálise Seção Rio de Janeiro. Doutor em Ciências Jurídicas e Sociais pela Universidade Federal Fluminense (PPGSD-UFF). pbrocco@uol.com.br.
} 
Santana transita de forma leve e instigante pelos domínios da filosofia e da psicanálise, fruto de uma sólida formação nestes dois campos. Sua perspectiva é a de articular uma leitura entre a obra de Nietzsche e a psicanálise, construindo ao longo do livro pontos de encontro entre as duas esferas e mostrando, com sucesso, que há um diálogo constante, e muitas vezes não reconhecido, entre Nietzsche e a teoria e clínica psicanalíticas. Santana aponta a afinidade entre Nietzsche e a psicanálise onde em ambas as obras se veem desenhar entre um (des)encontro entre a positividade das pulsões e um ponto ausente: a vontade de potência e o niilismo, no caso de Nietzsche, e a pulsão e Das Ding, no caso da psicanálise. A articulação proposta por Santana não é apenas de caráter conceitual mas, como o próprio autor reconhece, trata-se de uma "articulação ética, em uma analogia ética fundada sobre um pressuposto comum que reúne Freud e Nietzsche: o encontro entre a pulsão e a ausência" (SANTANA, 2019, p. 27).

Sabe-se que Freud já conhecia a obra de Nietzsche desde ao menos 1908, de acordo com as atas da Sociedade Psicanalítica de Viena, quando aí se discutiu "O ideal ascético", terceira parte da Genealogia da moral (CHECCHIA; TORRES; HOFFMANN [Orgs.], 2015, pp. 510-518).

Quais linhas de influência e de recepção poderiam configurar um ponto de contato, na tradição filosófica, entre Nietzsche e Freud? Santana reconhece que ambos são tributários de Arthur Schopenhauer:

Tanto Nietzsche quanto Freud, herdeiros de Schopenhauer, erigiram suas obras em contraponto às leituras afeitas à consciência e, ao invés de privilegiarem a razão no que esta se alinha a uma lógica do pensamento consciente, primaram por uma leitura centrada na noção de pulsão (Trieb), por meio da qual desferiram um golpe ao narcisismo humano (SANTANA, 2019, p. 27).

Freud e Nietzsche são reconhecidos como dois autores que, assim como Schopenhauer, localizam a sexualidade e as pulsões que atravessam os corpos como elo fundamental para pensar o caráter geral do mundo e da vida. Isso levará Santana a, através de Freud, Lacan e Nietzsche, tecer suas variações em torno de questões como o niilismo, a crítica à ontologia, a morte de Deus, o desejo, a pulsão e a ética trágica, bem como os sintomas e sofrimentos humanos. Sua perspectiva - e esta é sua tese -, ao contrário das interpretações de Deleuze e de Heidegger, é a de apontar a existência do negativo na obra de Nietzsche em coexistência com a positividade da 
dinâmica das pulsões: a vontade de potência (em constante diálogo com o conceito de pulsão da psicanálise).

O livro, que se divide em duas partes, "De Nietzsche" e "Da Psicanálise", traz logo no início um interessante trecho de Tristes trópicos, envolvendo um diálogo entre Claude Lévi-Strauss e o embaixador brasileiro em Paris, no ano de 1934, quando foi assegurado a Lévi-Strauss que não existiam mais índios no Brasil havia muitos anos. Segundo o embaixador brasileiro, "indo em direção aos índios, o que Lévi-Strauss encontraria seria o nada, o vazio, o nada post-mortem, lastro dos índios mortos e que, portanto, agora se encontrariam como pontos ausentes em seu campo de visão" (SANTANA, idem, p. 25).

Os índios brasileiros (inexistentes para o então embaixador) seriam muito bem localizados por Lévi-Strauss, que construiria parte fundamental de sua obra a partir de suas pesquisas no Brasil, as quais levariam ao adensamento e aprofundamento de sua teoria e ao desenvolvimento do estruturalismo, com grande impacto nas ciências humanas e na psicanálise feita por Jacques Lacan. Santana nos apresenta então uma pergunta fundamental neste diálogo entre Lévi-Strauss e o embaixador brasileiro: como do nada se passou ao ser? Pois se o embaixador nada via e o antropólogo francês via muitas coisas, para Santana a pergunta se desloca do ponto de vista meramente ontológico para o campo da ética: nas malhas do desejo e da pulsão, a questão principal não se localiza muito na pergunta $o$ que é?, mas mais ainda sobre o que queres?, conforme pergunta Lacan em seu seminário sobre a ética da psicanálise.

É pelo princípio do prazer que o psiquismo começa a funcionar. É pelo fato deste princípio não dar conta de tudo, pois nele a experiência se repete pela alucinação do objeto ausente, que o sujeito dá um passo a mais e sofistica sua representação pelo princípio da realidade: não apenas a identidade de percepção, mas de pensamento. A possibilidade de encontrar satisfação para além da mera percepção trata da elaboração do desejo pela fantasia, e trata também da importância da psicanálise neste sentido.

Santana observa que é na dimensão da ética que Nietzsche elabora suas reflexões sobre a moral quando se preocupa antes pelo "valor" em detrimento da pergunta pelo "ser": antes de saber o que é a vida, importa a Nietzsche mais saber qual o valor atribuído a ela (SANTANA, idem, p. 26). Esta forma de encarar a realidade teria reverberações na psicanálise, para a qual não está em questão a pergunta pelo 
"ser", isto é, uma ontologia, mas uma pergunta pelo desejo, pelo Che vuoi? que concerne a cada sujeito.

A pergunta pelo valor atribuído a algo também poder ser lida a partir da chave do desejo atribuído a algo - em outras palavras, o deslocamento da pergunta pelo ser para uma pergunta pelo desejo, pelo a que o desejo está ligado, ao que ele diz "sim" e ao que diz "não": tal deslocamento de uma ontologia do ser para uma ética do desejo está na base do livro de Bruno Santana.

O vazio de sentido a partir do qual o ser humano percebe o mundo no momento em que ocorre a operação simbólica da morte (ou esvaziamento) de Deus como garantidor de uma consistência ontológica do mundo, da realidade e da história, tema fundamental em Nietzsche, em verdade vinha já se insinuando para a Europa renascentista desde meados do século XVI, quando os jesuítas entraram em contato com a tradição taoísta e zen-budista no Extremo Oriente, sobretudo, em um primeiro momento, com os monges zen japoneses. Ficaram horrorizados com o fato de que, ao contrário dos missionários europeus, aristotélico-tomistas e cultivadores da razão que eram, os monges zen japoneses não colocavam como fundamento das coisas e do ser a ideia de Deus, mas a ideia de Vazio.

A noção de Vazio se coloca no Tao te ching ligada à de utilidade, quando Laotse escreve sobre o vazio no centro da roda, do vaso e da casa (LAO TSE, [350-250 a.C] 1999):

\footnotetext{
Trinta raios convergem ao vazio do centro da roda

Através dessa não-existência

Existe a utilidade do veículo.

A argila é trabalhada na forma de vasos

Através da não-existência

Existe a utilidade do objeto.

Portas e janelas são abertas na construção da casa

Através da não-existência

Existe a utilidade da casa.

Assim, da existência vem o valor

E da não-existência, a utilidade.
}

Assim, a noção de vazio representa também para a tradição oriental o fundamento de sua escrita: a partir do vazio, o traço significante.

Desenvolvendo esta concepção, poderíamos dizer que a História humana, por exemplo, não seria um desdobramento, no plano humano, de uma espécie de Ditado 
divino, mas uma escrita coletiva cujo centro ausente repousaria em um vazio fundamental.

De uma forma interessante e convergente, Bruno Santana nos apresenta Nietzsche e a psicanálise em diálogo e tocados, de alguma maneira, pela tradição oriental que começa a se insinuar na Europa no campo da filosofia e de modo especial a partir de Schopenhauer².

O vazio lido por Santana e articulado à psicanálise e Nietzsche estará presente em um movimento: de um lado, a positividade das pulsões "no que elas são, segundo Freud, sempre ativas do ponto de vista da pressão que exercem e cuja fonte se localiza no corpo" (SANTANA, 2019, p. 29), consideradas do ponto de vista nietzschiano como expressão do mundo como vontade de potência; de outro lado, o encontro com a falta, com o que do real escapa à linguagem, deixando lugar para a falta de sentido e a falta de um objeto último que garanta uma satisfação plena e capaz de fazer cessar a atividade desejante.

O deslocamento do capítulo dedicado à pulsão a partir da psicanálise para o da ética, marcando que a psicanálise se orienta por uma ética trágica, na medida em que parte da positividade das pulsões, faz um duplo movimento de colocar em xeque a ética aristotélica orientada pelo Bem e reafirmar o gume cortante da psicanálise ou, como afirma o autor: "Trágico é poder desejar - para além do bem e do mal, do melhor e do pior" (SANTANA, idem, pp. 117-118).

Ao escrever por meio de variações, tais como as compostas por Bach e executadas por Goldberg, estabelecendo repetições harmônicas das composições de Nietzsche e da Psicanálise, Bruno Santana faz em Variações do ver mais do que meramente estabelecer paralelos entre a obra nietzschiana e a teoria psicanalítica, mas executa com mestria sua própria peça, suas próprias variações, tecendo com sua escrita singular algo novo.

\footnotetext{
2 Schopenhauer foi o primeiro filósofo do Ocidente a propor um diálogo entre a filosofia oriental, sobretudo o budismo e a tradição védica, e a filosofia ocidental de inspiração platônico-kantiana (cf. a Apresentação de Jair Barboza na edição citada ao final desta resenha). Em O mundo como vontade e como representação, chega a afirmar que o conhecimento exposto nos Vedas é fruto do mais elevado conhecimento e sabedoria humanos (SCHOPENHAUER, [1819] 2005, p. 453).
} 


\section{REFERÊNCIAS}

Variações do ver: uma articulação entre Psicanálise e Nietzsche. SANTANA, Bruno W. Curitiba: CRV, 2019.

CHECCHIA, Marcelo; TORRES, Ronaldo; HOFFMANN, Waldo (Orgs.). Os primeiros psicanalistas: Atas da Sociedade Psicanalítica de Viena (1906-1908). Tradução de Marcella Marino Medeiros Silva. São Paulo: V. de Moura Mendonça - Livros (Scriptorium), 2015. (Atas da Sociedade Psicanalítica de Viena, Volume 1).

LAO-TSE. Tao Te Ching: o livro do caminho e da virtude. Tradução do chinês por Wu Jyh Cherng. Rio de Janeiro: Mauad, 1999.

SANTANA, Bruno W. Variações do ver: uma articulação entre Psicanálise e Nietzsche. Curitiba: CRV, 2019.

SCHOPENHAUER, Arthur. O mundo como vontade e como representação, I ${ }^{\circ}$ tomo. Tradução, apresentação, notas e índices de Jair Barboza. São Paulo: Editora UNESP, 2005. 
RECEBIDO EM 27/11/2019

APROVADO EM 22/06/2020

(C) 2020 Psicanálise \& Barroco em revista

http://www.seer.unirio.br/index.php/psicanalise-barroco/index

revista@psicanaliseebarroco.pro.br

Programa de Pós-Graduação em Memória Social — UNIRIO

Memória, Subjetividade e Criação

www.memoriasocial.pro.br/proposta-area.php 